\title{
Hypereutectic Al-Ca-Mn-(Ni) Alloys as Natural Eutectic Composites
}

\author{
Evgeniya Naumova ${ }^{1, *}$, Vitali Doroshenko ${ }^{1}$, Mikhail Barykin ${ }^{1}$, Tatyana Sviridova ${ }^{2}$, Alexandra Lyasnikova ${ }^{3}$ \\ and Pavel Shurkin ${ }^{1}$ (D)
}

1 Department of Metal Forming, National University of Science and Technology MISiS, Leninsky Ave. 4, 119049 Moscow, Russia; v.doroshenko@mail.ru (V.D.); mr.barykin97.97@mail.ru (M.B.); pa.shurkin@gmail.com (P.S.)

2 Department of Physical Materials Science, National University of Science and Technology MISiS, Leninsky Ave. 4, 119049 Moscow, Russia; tim-17@yandex.ru

3 Department of Biotechnical and Medical Systems and Technologies, Don State Technical University, Gagarin Square 1, 344000 Rostov-on-Don, Russia; kafbma2011@yandex.ru

* Correspondence: jan73@mail.ru; Tel.: +7-9163116927

check for updates

Citation: Naumova, E.; Doroshenko, V.; Barykin, M.; Sviridova, T.; Lyasnikova, A.; Shurkin, P. Hypereutectic Al-Ca-Mn-(Ni) Alloys as Natural Eutectic Composites. Metals 2021, 11, 890. https://doi.org/ $10.3390 /$ met11060890

Academic Editor: Tilmann Beck

Received: 27 April 2021

Accepted: 26 May 2021

Published: 29 May 2021

Publisher's Note: MDPI stays neutral with regard to jurisdictional claims in published maps and institutional affiliations.

Copyright: (c) 2021 by the authors. Licensee MDPI, Basel, Switzerland. This article is an open access article distributed under the terms and conditions of the Creative Commons Attribution (CC BY) license (https:// creativecommons.org/licenses/by/ $4.0 /)$.

\begin{abstract}
In the present paper, Natural Metal-Matrix Composites (NMMC) based on multicomponent hypereutectic Al-Ca-(Mn)-(Ni) alloys were studied in as-cast, annealed and rolled conditions. ThermoCalc software and microstructural observations were utilised for analysing the equilibrium and actual phase composition of the alloys including correction of the Al-Ca-Mn system liquidus projection and the solid phase distribution in the Al-Ca-Mn-Ni system. A previously unknown $\mathrm{Al}_{10} \mathrm{CaMn}_{2}$ was discovered by both electron microprobe analysis and X-ray studies. The Al-6Ca-3Mn, $\mathrm{Al}-8 \mathrm{Ca}-2 \mathrm{Mn}$, Al-8Ca-2Mn-1Ni alloys with representative NMMC structure included ultrafine Ca-rich eutectic and various small-sized primary crystals were found to have excellent feasibility of rolling as compared to its hypereutectic Al-Si counterpart. What is more, Al-Ca alloys showed comparable Coefficient of Thermal Expansion values due to enormous volume fraction of Al-based eutectic and primary intermetallics. Analysis of tensile samples' fracture surfaces revealed that primary intermetallics may act either as stress raisers or malleable particles depending on their stiffness under deformation. It is shown that a compact morphology can be achieved by conventional casting without using any refining agents. Novel hypereutectic Al-Ca NMMC materials solidifying with the formation of $\mathrm{Al}_{10} \mathrm{Mn}_{2} \mathrm{Ca}$ primary compound have the best ductility and strength. We reasonably propose these materials for high-load pistons.
\end{abstract}

Keywords: hypereutectic aluminium alloys; Al-Ca alloys; phase composition; structure; intermetallics; rolling; physical and mechanical properties

\section{Introduction}

Currently, light materials with a given set of mechanical and physical properties are extremely in demand for manufacturing engineering parts [1-3]. Specifically, high-load pistons operated at up to $300{ }^{\circ} \mathrm{C}$ require not only specific mechanical properties (e.g., strength, hardness and ductility) but also low Coefficient of Thermal Expansion (CTE) and high thermal conductivity. Among numerous materials, hypereutectic Al-Si alloys (e.g., A390.0 and FM180 alloys), have been established due to acceptable performance in the aforementioned properties $[1,4,5]$. In reality, they are natural metal matrix composites (NMMC) consisting of hard (Si) crystals distributed throughout a eutectic matrix. However, they show some pivotal drawbacks such as brittleness and the need for modification operation for refining primary and eutectic (Si) phase $[1,5]$.

In the present study, alternative Al-Ca alloys are proposed which were recently reported with excellent processability through shape casting and metal forming [6-10]. When considering hypoeutectic Al-Ca alloys, they have low density, an appropriate combination 
of mechanical properties and corrosion resistance [6,8]. Meanwhile, their phase composition is complicated and available thermodynamic data are relatively poor. Specifically, there is a lack in the ternary Al-Ca-X phase diagrams not to mention the quaternary systems Al-Ca-X-Y. In our previous studies, many ternary Ca-rich compounds were found including those previously unknown $[7,9,11,12]$. Their primary crystallisation depending on the composition matters for the design of the hypereutectic alloys. Initially, we find it expedient to develop the multicomponent phase diagrams in the regions for hypereutectic alloys is of profound scientific importance for designing novel materials.

It should be noted that a remarkably fine as-cast eutectic structure in the $\mathrm{Al}-\mathrm{Ca}$ alloys can be achieved without any refining agents. Moreover, multicomponent eutectic can appear to be even thinner in comparison to a binary $\left[(\mathrm{Al})+\mathrm{Al}_{4} \mathrm{Ca}\right]$ eutectic. The work [13] reported Al-Ca-Mn-Fe alloys with a set of superfine multiphase eutectics (ternary and quaternary) that provides a high-tech performance in casting and metal forming. It should be noted that the best metal forming processability was shown for Al-Ca-Mn alloys [14]. Moreover, Mn acts both as a eutectic-forming element and a solid-solution strengthening agent $[1,15]$. As for $\mathrm{Al}-\mathrm{Ca}-\mathrm{Ni}$ alloys, an appearance of the ternary $\mathrm{Al}_{9} \mathrm{NiCa}$ phase together with $\mathrm{Al}_{4} \mathrm{Ca}$ and $\mathrm{Al}_{3} \mathrm{Ni}$ phases was found in equilibrium with (Al) solid solution [9]. Being a part of the eutectic mixture [( $\left.\mathrm{Al})+\mathrm{Al}_{4} \mathrm{Ca}+\mathrm{Al}_{9} \mathrm{NiCa}\right]$, the ternary compound has a submicron size and demonstrates a response to spheroidising annealing. Primary $\mathrm{Al}_{9} \mathrm{NiCa}$ crystals exhibit a polyhedron shape that is similar to the primary (Si) phase in the hypereutectic Al-Si alloys [4]. When considering a detailed investigation of the primary crystals' shape in the multicomponent Al-Ca alloys, there has been virtually no relevant research so far. Within the range of various compounds, some may primarily solidify acquiring a compact shape without compromising the ductility but increasing both strength and the CTE value. It is known that hypereutectic Al-Si alloys are manufactured by either squeeze casting or isothermal hot stamping or hot extrusion [4]. However, massive (Si) primary crystals deteriorate the plasticity of alloys. For this reason, special approaches are being developed for refining primary crystals $[1,4,5]$. For ensuring processability of hypereutectic alloys through deformation, small size $(50-70 \mu \mathrm{m})$ and uniformity in distribution of primary crystals must be maintained as well as a globular shape of eutecticorigin intermetallics as illustrated in Figure 1. Based on the preliminary results, we reasonably find hypereutectic multicomponent $\mathrm{Al}-\mathrm{Ca}$ alloys very appropriate for designing NMMC materials with special physical and mechanical properties competitive to those of the Al-Si piston alloys.

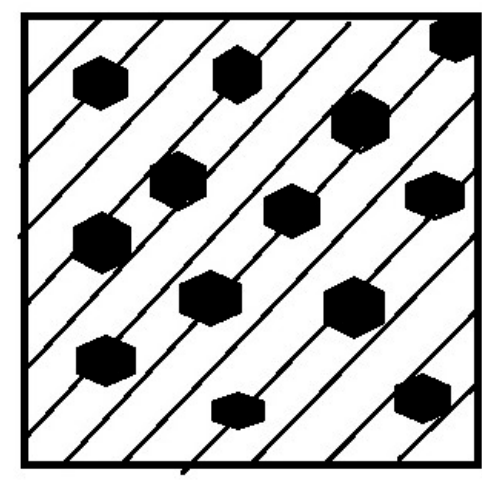

(a)

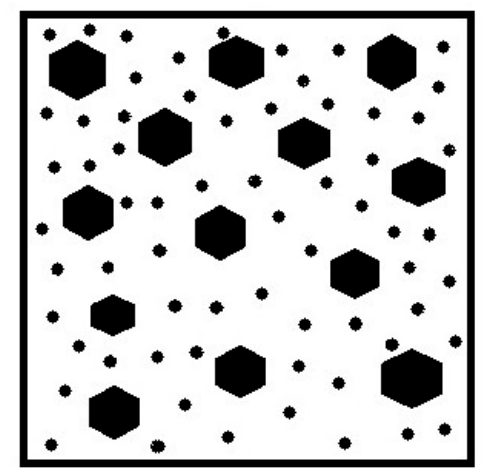

(b)

Figure 1. Schematic representation of the target NMMC microstructure: (a) as-cast condition; (b) after spheroidising annealing.

The aim of this work is to explore promising hypereutectic Al-Ca alloys and study their structure and properties with Mn and Ni alloying. 


\section{Materials and Methods}

The experimental alloys (Table 1) were prepared in an electric resistance furnace LAC (LAC, s.r.o., Židlochovice, Czech Republic) using pure aluminium $(99.99 \% \mathrm{Al})$, calcium $(99.99 \% \mathrm{Ca})$, silicon $(99.99 \% \mathrm{Si})$ and $\mathrm{Al}-20 \% \mathrm{Ni}$ and $\mathrm{Al}-20 \% \mathrm{Mn}$ master alloys. For the sake of comparison, a commercial AlSi18Cu1Mg1Ni1 (FM180) piston alloy was prepared. The molten alloys were poured at $730-750{ }^{\circ} \mathrm{C}$ into a graphite mould (without preheating) with an inner size of $15 \mathrm{~mm} \times 30 \mathrm{~mm} \times 180 \mathrm{~mm}$. The cooling rate under that conditions was about $10 \mathrm{~K} / \mathrm{s}$.

Table 1. Chemical composition of the experimental alloy.

\begin{tabular}{|c|c|c|c|c|}
\hline \multirow{2}{*}{ Designation } & \multicolumn{4}{|c|}{ Concentrations, wt. $\%$} \\
\hline & $\mathrm{Ca}$ & Mn & $\mathbf{N i}$ & Al \\
\hline Al-3Ca-2Mn & 3 & 2 & - & Balance \\
\hline Al-6Ca-1.5Mn & 6 & 1.5 & - & Balance \\
\hline Al-6Ca-2Mn & 6 & 2 & - & Balance \\
\hline Al-6Ca-3Mn & 6 & 3 & - & Balance \\
\hline Al-8Ca-0.5Mn & 8 & 0.5 & - & Balance \\
\hline Al-8Ca-2Mn & 8 & 2 & - & Balance \\
\hline Al-8Ca-3Mn & 8 & 3 & - & Balance \\
\hline $\mathrm{Al}-10 \mathrm{Ca}$ & 10 & 0 & - & Balance \\
\hline Al-10Ca-1.5Mn & 10 & 1.5 & - & Balance \\
\hline Al-10Ca-2.5Mn & 10 & 2.5 & - & Balance \\
\hline Al-8Ca-2Mn-1Ni & 8 & 2 & 1 & Balance \\
\hline Al-8Ca-2Mn-2Ni & 8 & 2 & 2 & Balance \\
\hline Al-8Ca-2Mn-3Ni & 8 & 2 & 3 & Balance \\
\hline Al-8Ca-2Mn-4Ni & 8 & 2 & 4 & Balance \\
\hline Al-6Ca-3Mn-2Ni & 6 & 3 & 2 & Balance \\
\hline AlSi18Cu1Mg1Ni1 (FM180) & $1 \mathrm{Cu}$ & 0.2 & $1 \mathrm{Ni}+1 \mathrm{Mg}$ & Balance \\
\hline
\end{tabular}

Heat treatment of ingots was carried out at $500{ }^{\circ} \mathrm{C}$ in a muffle electric furnace SNOL 8.2/1100 (Umega Group, $\mathrm{AB}$, Utena, Lithuania) with a temperature deviation of about $3^{\circ} \mathrm{C}$. This procedure is necessary for increasing the plasticity of ingots by fragmentation and spheroidisation of eutectic intermetallics. Hot rolling of ingots was carried out at a speed of $0.2 \mathrm{~m} / \mathrm{s}$ on a reversible laboratory duo-mill with a maximum rolling width of $250 \mathrm{~mm}$. An initial ingot's thickness was $15 \mathrm{~mm}$. We conducted rolling with a $10 \%$ reduction for each pass and an average total reduction ratio of $80 \%$.

The microstructure was examined by scanning electron microscopy (SEM, TESCAN VEGA3, Tescan Orsay Holding, Brno, Czech Republic) equipped with an electron microprobe analysis (EMPA, Oxford Instruments plc, Abingdon, UK), and the Aztec software (Oxford Instruments plc, Abingdon, UK). Thermo-Calc software (TTAL5 database) was used to calculate the phase composition of the alloys [16]. Actual phase transformation temperatures were determined using a DSC 404 F1 Pegasus differential scanning calorimeter (Netzsch Group, Selb, Germany). X-ray analysis was carried out on a Bede D1 System (Bruker, Karlsruhe, Germany) with $\mathrm{Cu} K \alpha$ radiation $(\lambda=0.15406 \mathrm{~nm})$ and treated by software package [17]. Electrical conductivity (EC) was determined using the eddy current method with a VE-26NP eddy structures instrument (CJSC Research institute of introscopy SPEKTR, Moscow, Russia). A high purity Al was employed for comparison purposes. Vickers hardness (HV) was determined using a Wilson Wolpert $930 \mathrm{~N}$ setup (Wilson Instruments, Instron Company, Norwood, MA, USA) at $50 \mathrm{~N}$ load and $10 \mathrm{~s}$ dwell time. Room temperature tensile tests for the sheet samples of $150 \mathrm{~mm} \times 12 \mathrm{~mm}$ in dimensions were carried out using a Zwick/Z 250 setup (Zwick Roell AG, Ulm, Germany). 


\section{Results and Discussion}

\subsection{Al-Ca-Mn Alloys}

Liquidus projection of the Al-Ca-Mn system (Figure 2) was calculated for substantiating the choice of the experimental hypereutectic alloys solidified under different phase fields. Experimental investigations were next conducted for revision of the isothermal boundaries. Since $\mathrm{Al}_{4} \mathrm{Ca}$ primary crystals were reported with coarse platelet shape [7], most of the selected compositions encountering crystallisation of the primary $\mathrm{Al}_{6} \mathrm{Mn}$ phase. Approximately 30-40 wt.\% intermetallics in the structure are expected to provide essential physical and mechanical properties.

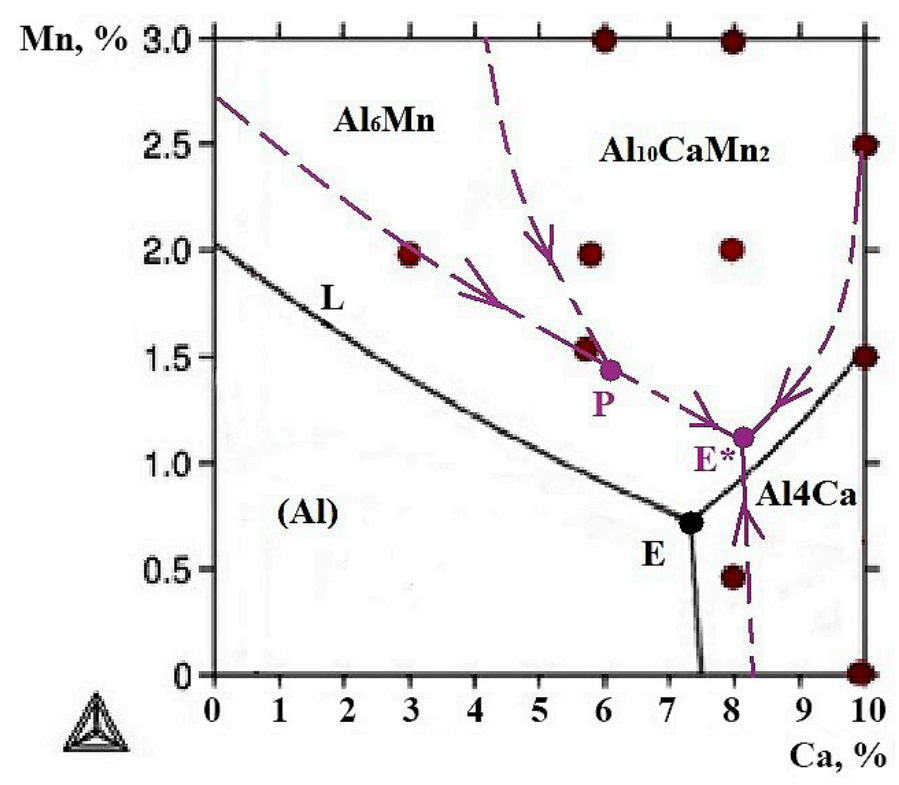

Figure 2. The predicted view of the Al-Ca-Mn phase diagram in the Al-rich region (solid linecalculation, dotted line-experiment).

Al-3Ca-2Mn, Al-6Ca-1.5Mn, Al-8Ca-0.5Mn and Al-10Ca-1.5Mn alloys are the closest to the phase-field boundaries. Microstructural observations and EMPA analysis of these alloys showed that Al-3Ca-2Mn alloy (Figure 3a) almost totally includes the colonies of the binary eutectic $\left[(\mathrm{Al})+\mathrm{Al}_{4} \mathrm{Ca}\right]$. Some insufficient $\mathrm{Al}_{6} \mathrm{Mn}$ particles (including some calcium as solute) are also observed in the structure, while according to the equilibrium conditions their amount should have been far larger. A very fine eutectic structure in the Al-6Ca-1.5Mn alloy is decorated by equiaxed crystals of the ternary compounds (Figure 3b), namely $\mathrm{Al}_{11} \mathrm{CaMn}_{2}$, as the latter was determined according to EMPA. It should be noted that this ternary compound is not counted in the Thermo-Calc calculation but its existence indicates one more phase field in the phase diagram. Furthermore, the Al-6Ca-1.5Mn alloy displays some primary crystals of the $\mathrm{Al}_{6} \mathrm{Mn}$ phase. The structure of the Al-8Ca$0.5 \mathrm{Mn}$ alloy (Figure $3 \mathrm{c}$ ) includes eutectic $\left[(\mathrm{Al})+\mathrm{Al}_{4} \mathrm{Ca}\right]$ and the primary $(\mathrm{Al})$ dendrites of a small fraction. The Al-10Ca-1.5Mn alloy exhibits primary $\mathrm{Al}_{4} \mathrm{Ca}$ crystals and a minor amount of the $\mathrm{Al}_{11} \mathrm{CaMn}_{2}$ phase. When considering the Al-10Ca-2.5Mn alloy (Figure 3e), primary $\mathrm{Al}_{4} \mathrm{Ca}$ and $\mathrm{Al}_{11} \mathrm{CaMn}_{2}$ phases co-exist in equal fractions due to apparent phasefield boundary composition. Ultimately, primary $\mathrm{Al}_{4} \mathrm{Ca}$ crystals and $\left[(\mathrm{Al})+\mathrm{Al}_{4} \mathrm{Ca}\right]$ fine binary eutectic are observed in the structure of the Al-10Ca alloy (Figure 3f). 


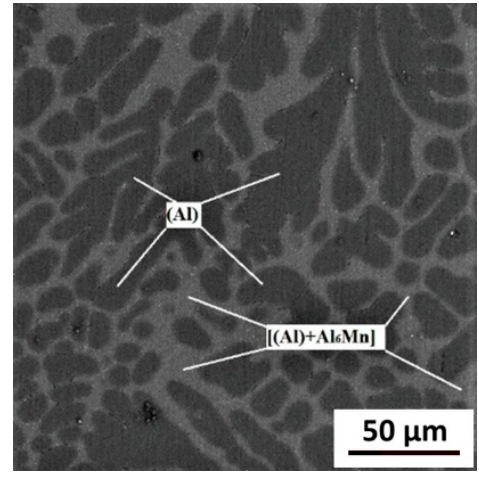

(a)

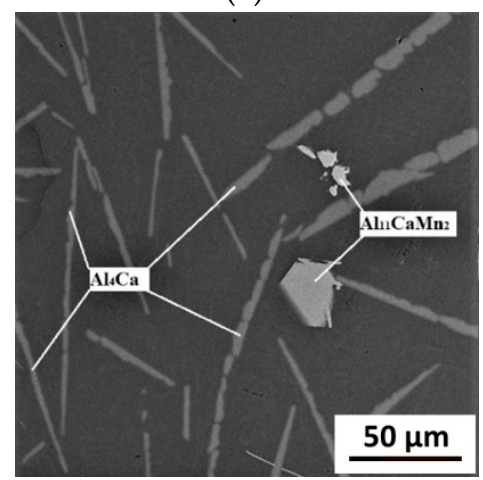

(d)

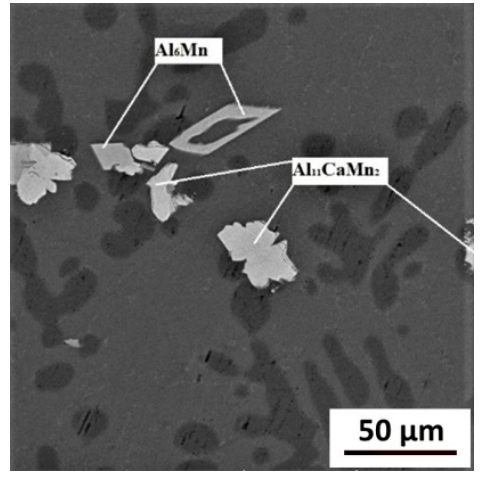

(b)

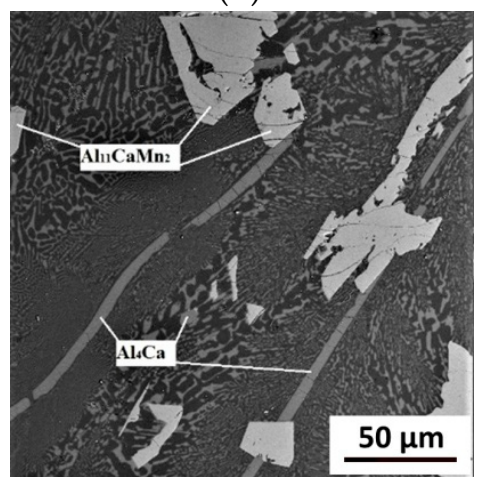

(e)

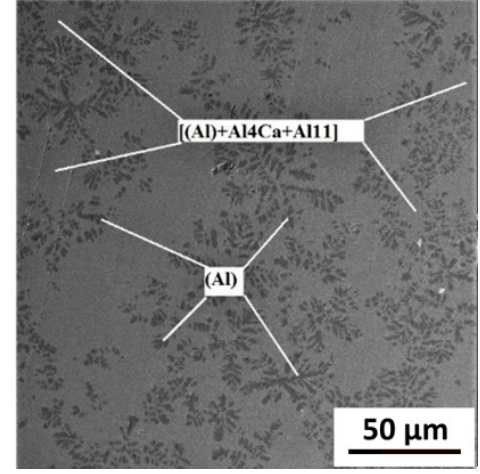

(c)

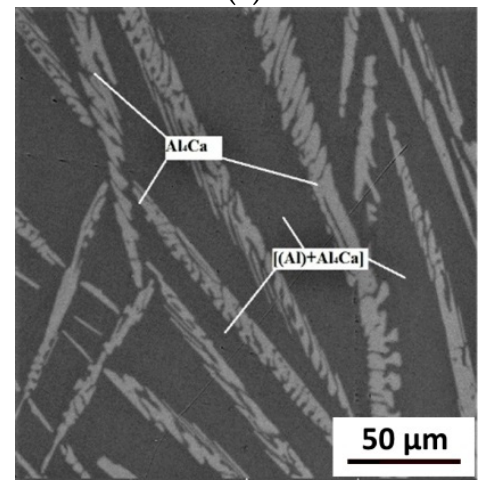

(f)

Figure 3. SEM images showing the microstructure of the experimental Al-Ca-Mn alloys in the as-cast condition: (a) Al-3Ca2Mn; (b) Al-6Ca-1.5Mn; (c) Al-8Ca-0.5Mn; (d) Al-10Ca-1.5Mn; (e) Al-10Ca-2.5Mn; (f) Al-10Ca.

According to the aforementioned investigations, we can reasonably propose a shift of isothermal lines and extension in the (Al) existence region as it is shown in Figure 2 (dotted line). Thus, an Al-rich angle liquidus projection has been predicted. In this regard, two nonvariant reactions including peritectic $\mathrm{L}+\mathrm{Al}_{6} \mathrm{Mn} \rightarrow(\mathrm{Al})+\mathrm{Al}_{10} \mathrm{Mn}_{2} \mathrm{Ca}$ (point $\mathrm{P}$ ) and eutectic $\mathrm{L} \rightarrow(\mathrm{Al})+\mathrm{Al}_{4} \mathrm{Ca}+\mathrm{Al}_{10} \mathrm{Mn}{ }_{2} \mathrm{Ca}$ (point $\mathrm{E}$ ) are expected.

The Al-6Ca-3Mn and Al-8Ca-2Mn alloys appeared to have the most favourable NMMC microstructure. Their solidification starts with the formation of the $\mathrm{Al}_{10} \mathrm{CaMn}_{2}$ phase (Figure 1a). In the Al-8Ca-2Mn alloy, a few compact angular crystals of $\mathrm{Al}_{6}(\mathrm{Mn}, \mathrm{Fe})$ appeared likely due to the presence of Fe impurity. According to the calculation and structural observations, these alloys manufactured under graphite mould gravity casting (cooling rate $10 \mathrm{~K} / \mathrm{s}$ ) exhibit approximately $40 \%$ intermetallics (Table 2). They consist of fine eutectic (containing approximately $8 \% \mathrm{Ca}$ and $1 \% \mathrm{Mn}$ ) and the $\mathrm{Al}_{10} \mathrm{CaMn}_{2}$ primary crystals ranged between 10 and $20 \mu \mathrm{m}$ in linear size (Figure 4a,b). The FM180 alloy counterpart prepared under the same conditions contains less than $20 \%$ (Si) crystals of more than 40-50 $\mu \mathrm{m}$ (Figure 4c). As the eutectic structure of the Al-6Ca-3Mn and Al-8Ca2Mn alloys is sufficiently thinner as compared to the FM180 alloy, spheroidising annealing may be utilised for improving ductility $[1,10]$. Some physical and mechanical properties are presented in Table 2. 


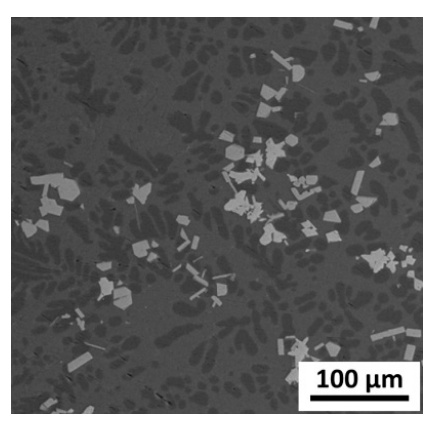

(a)

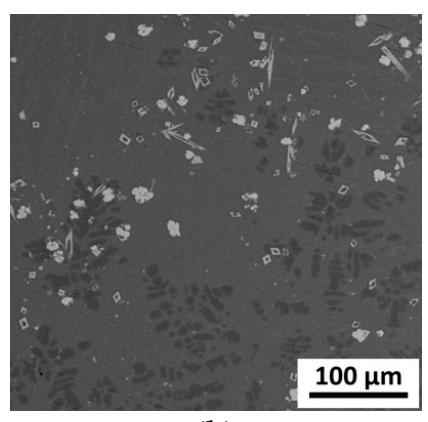

(b)

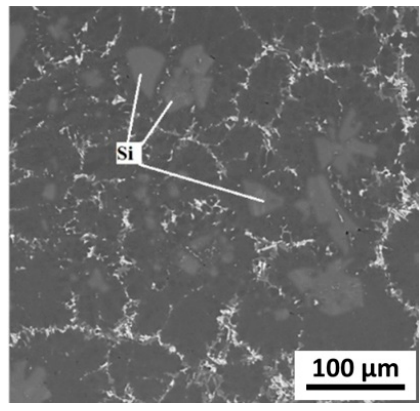

(c)

Figure 4. SEM images showing the microstructure of the experimental as-cast alloys showing a natural composite structure and FM180 alloy: (a) Al-6Ca-3Mn; (b) Al-8Ca-2Mn; (c) FM180.

Table 2. Calculated phase transformation temperatures, hardness and electrical conductivity of the as-cast Al-Ca-Mn alloys.

\begin{tabular}{cccccc}
\hline Alloy & $\mathbf{T}_{\mathbf{L}}$ & $\mathbf{T}_{\mathbf{S}}$ & $\Delta \mathbf{T}$ & $\mathbf{H V}$ & ${ }^{*} \mathbf{\Omega}, \mathbf{M S m} / \mathbf{m}$ \\
\hline Al-6Ca-1.5Mn & 665 & 611 & 54 & $70 \pm 2$ & $10.64 \pm 0.01$ \\
\hline Al-6Ca-2Mn & 686 & 611 & 75 & $77 \pm 3$ & $9.45 \pm 0.02$ \\
\hline Al-6Ca-3Mn & 721 & 611 & 110 & $72 \pm 4$ & $10.98 \pm 0.01$ \\
\hline Al-8Ca-2Mn & 700 & 611 & 89 & $82 \pm 2$ & $9.43 \pm 0.03$ \\
\hline Al-8Ca-0.5Mn & 622 & 611 & 11 & $63 \pm 3$ & $13.46 \pm 0.01$ \\
\hline Al-8Ca-3Mn & 735 & 611 & 124 & $78 \pm 4$ & $9.60 \pm 0.01$ \\
\hline Al-10Ca-1.5Mn & 689 & 611 & 77 & $93 \pm 3$ & $6.72 \pm 0.12$ \\
\hline Al-10Ca-2.5Mn & 730 & 611 & 119 & $114 \pm 10$ & $8.37 \pm 0.02$ \\
\hline
\end{tabular}

* hereinafter electrical conductivity is designated as $\Omega$.

Instead of the $\mathrm{Al}_{11} \mathrm{CaMn}_{2}$ compound roughly estimated by EMPA, the $\mathrm{Al}_{10} \mathrm{Mn}_{2} \mathrm{Ca}$ compound with a precise atomic composition was determined by $\mathrm{X}$-ray analysis. The latter was utilised for the Al-6Ca-3Mn alloy solidified in furnace ambience as it shows a far larger fraction (12.4 vol.\%) of the large ternary phase in the structure (Figure 5a). While the X-ray database does not contain the foregoing phase, the latter is known for the related systems $\mathrm{CaCr}_{2} \mathrm{Al}_{10}$ and $\mathrm{YMn}_{2} \mathrm{Al}_{10}[18,19]$. A crystal lattice belongs to the $\mathrm{tP5} / 2$ space group and has the parameters $\mathrm{a}=1.2845 \mathrm{~nm}, \mathrm{c}=0.5134 \mathrm{~nm}$ (Figure $5 \mathrm{~b}$ ).
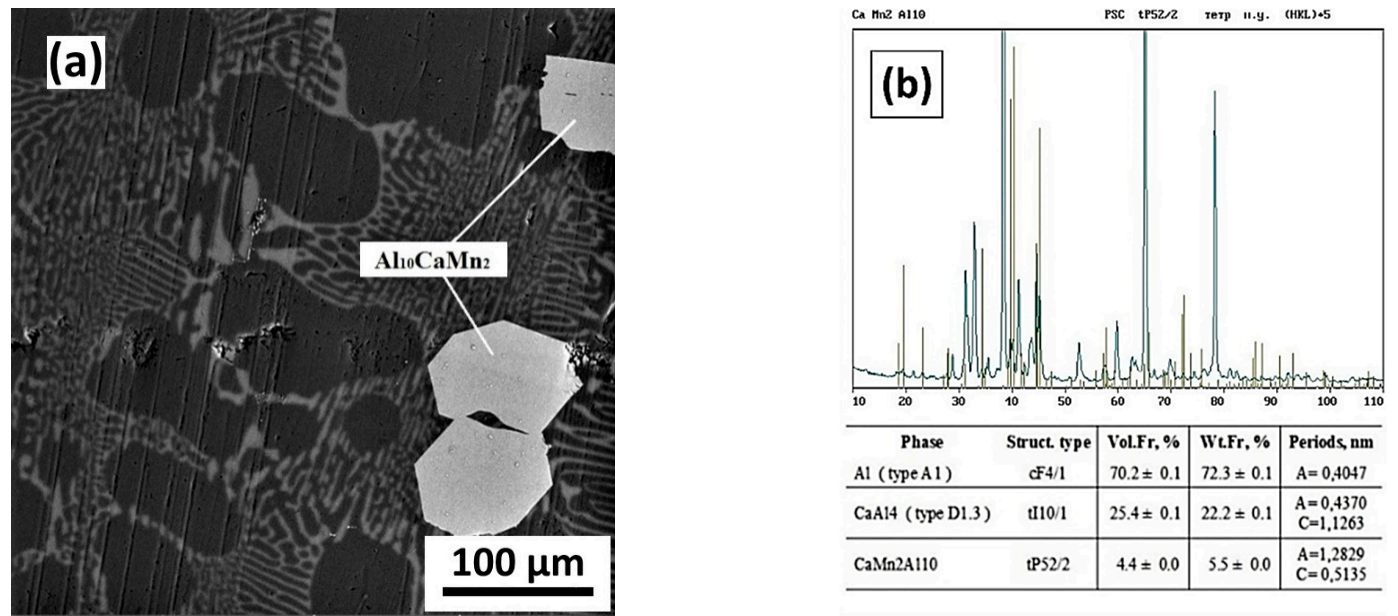

Figure 5. SEM images showing the $\mathrm{Al}_{10} \mathrm{Mn}_{2} \mathrm{Ca}$ crystals appeared in the Al-6Ca-3Mn alloy after furnace cooling (a) and $X$-ray analysis data identified the $\mathrm{Al}_{10} \mathrm{Mn}_{2} \mathrm{Ca}$ compound (b). 


\subsection{Al-Ca-Mn-Ni Alloys}

In a prior study [12], $\mathrm{Al}-\mathrm{Ca}-\mathrm{Ni}$ alloys were reported with a ternary $\mathrm{Al}_{9} \mathrm{CaNi}$ compound primary, crystals of which have a compact shape. It was assumed that nickel could improve the complex physical and mechanical properties of Al-Ca-Mn ternary alloys. Accordingly, Al-8Ca-2Mn-(1-4)Ni alloys were studied in detail (Table 1). The calculated liquidus projection of the Al-Ca-Mn-Ni system at $8 \%$ Ca is shown in Figure 6. Some physical and mechanical properties of the as-cast alloys are presented in Table 3.

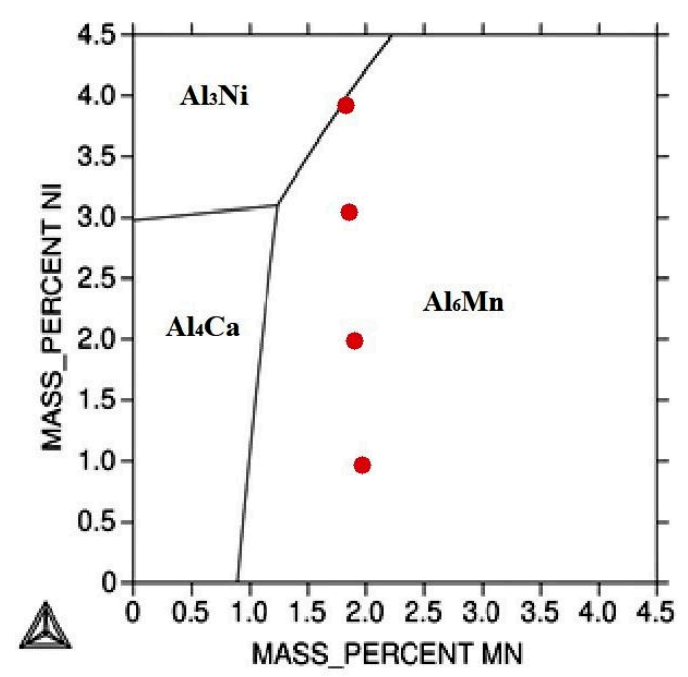

Figure 6. Calculated liquidus projection of the Al-Ca-Mn-Ni system at $8 \%$ Ca.

Table 3. Calculated phase transformation temperatures, hardness and electrical conductivity of the as-cast Al-Ca-Mn-Ni alloys.

\begin{tabular}{cccccc}
\hline Alloy & $\mathbf{T}_{\mathbf{L}}$ & $\mathbf{T}_{\mathbf{S}}$ & $\boldsymbol{\Delta T}$ & $\mathbf{H V}$ & $\mathbf{\Omega}, \mathbf{M S m} / \mathbf{m}$ \\
\hline Al-8Ca-2Mn-1Ni & 699 & 592 & 107 & $97 \pm 3$ & $9.51 \pm 0.02$ \\
\hline Al-8Ca-2Mn-2Ni & 699 & 607 & 92 & $98 \pm 3$ & $9.18 \pm 0.02$ \\
\hline Al-8Ca-2Mn-3Ni & 700 & 607 & 93 & $100 \pm 3$ & $9.12 \pm 0.02$ \\
\hline Al-8Ca-2Mn-4Ni & 700 & 607 & 93 & $103 \pm 3$ & $7.00 \pm 0.02$ \\
\hline AlSi18Cu1Mg1Ni1 (FM180) & 567 & 534 & 123 & $109 \pm 3$ & $13,7 \pm 0,02$ \\
\hline
\end{tabular}

The Al-8Ca-2Mn-1Ni alloy solidified in the furnace ambience exhibits two types of primary crystals including grey-coloured $\mathrm{Al}_{4}$ Ca platelets and compact bright $\mathrm{Al}_{10} \mathrm{CaMn}_{2}$ crystals (Figure 7a). The latter contains a minor amount of nickel which likely substitutes manganese. In addition, ternary $\left[(\mathrm{Al})+\mathrm{Al}_{4} \mathrm{Ca}+\mathrm{Al}_{8} \mathrm{Ca}(\mathrm{Ni}, \mathrm{Mn})_{2}\right]$ and binary $\left[(\mathrm{Al})+\mathrm{Al}_{4} \mathrm{Ca}\right]$ eutectics are observed in the structure. Due to the increase in the mean atomic number the Ni-rich phase is brighter in the BSE image as compared to other phases. EMPA revealed that some $\mathrm{Mn}$ dissolves in the $\mathrm{Al}_{8} \mathrm{CaNi}_{2}$ phase. In the furnace cooled $\mathrm{Al}-6 \mathrm{Ca}-3 \mathrm{Mn}-1 \mathrm{Ni}$ alloy, the primary $\mathrm{Al}_{8} \mathrm{Ca}(\mathrm{Ni}, \mathrm{Mn})_{2}$ crystals have a compact shape and linear size of less than $10 \mu \mathrm{m}$ (Figure $7 \mathrm{~b}$ ). Apart from the primary crystals, the presence of two binary eutectics $\left[(\mathrm{Al})+\mathrm{Al}_{4} \mathrm{Ca}\right]$ and $\left[(\mathrm{Al})+\mathrm{Al}_{8} \mathrm{Ca}(\mathrm{Ni}, \mathrm{Mn})_{2}\right]$ is detected. 


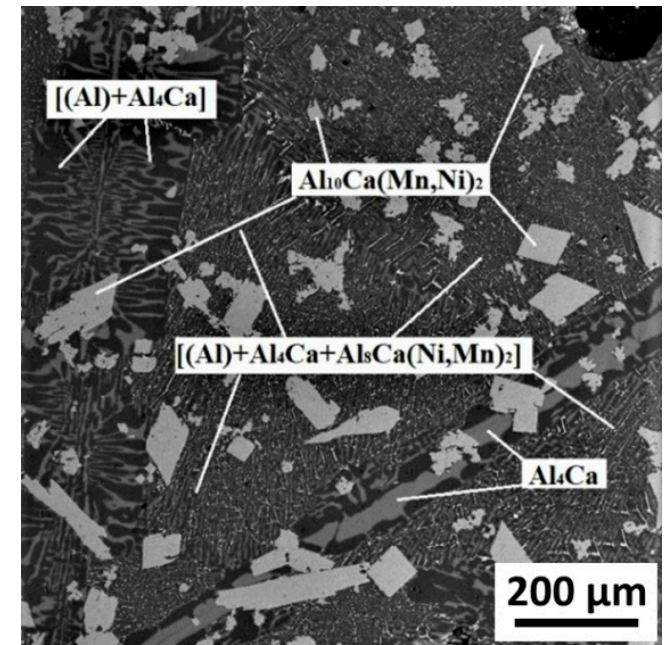

(a)

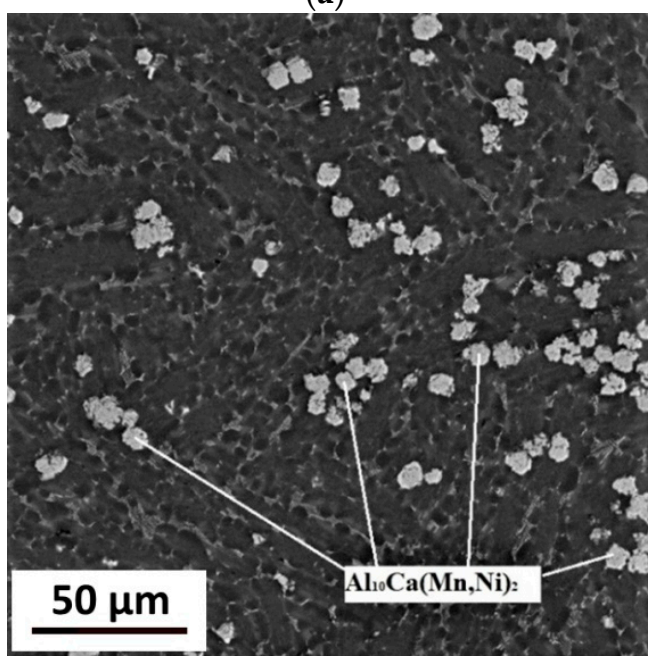

(c)

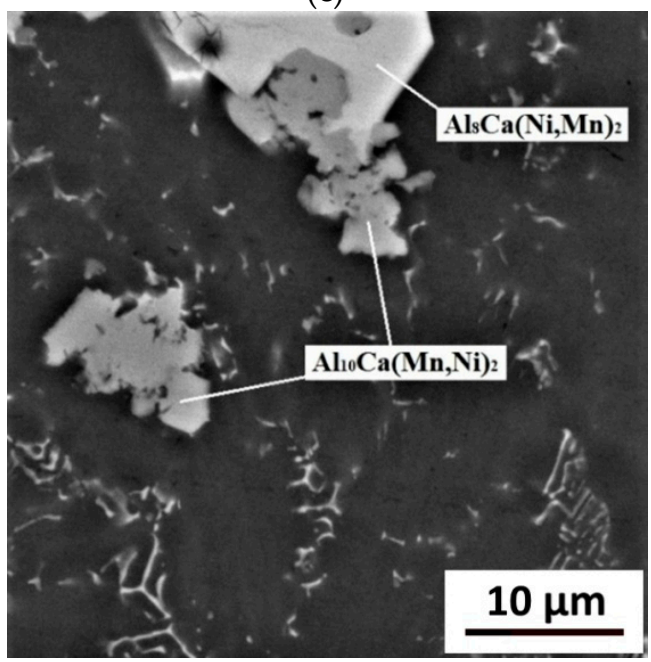

(e)

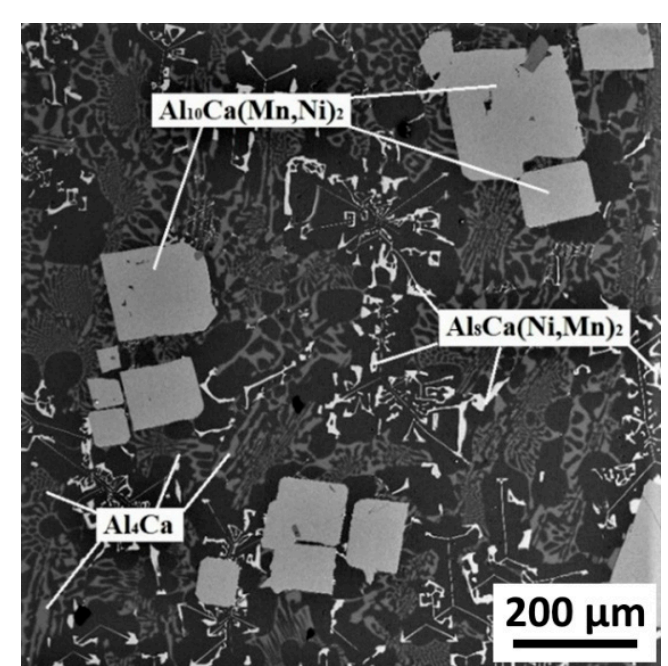

(b)

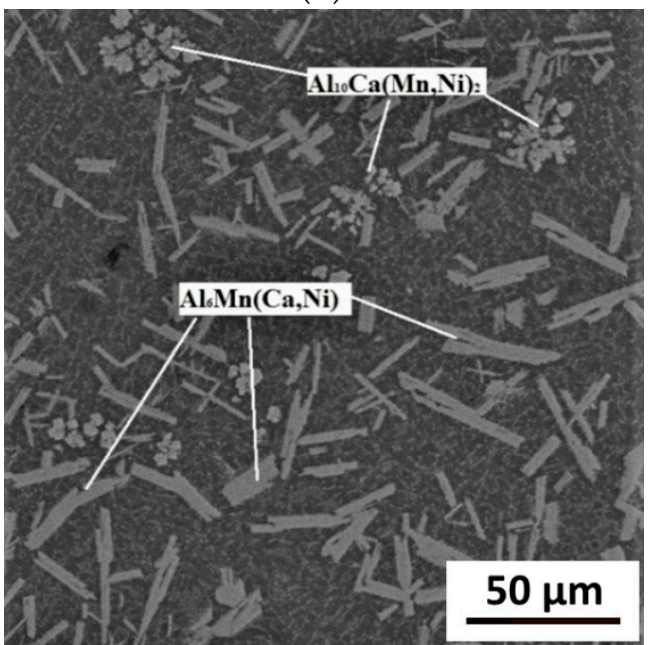

(d)

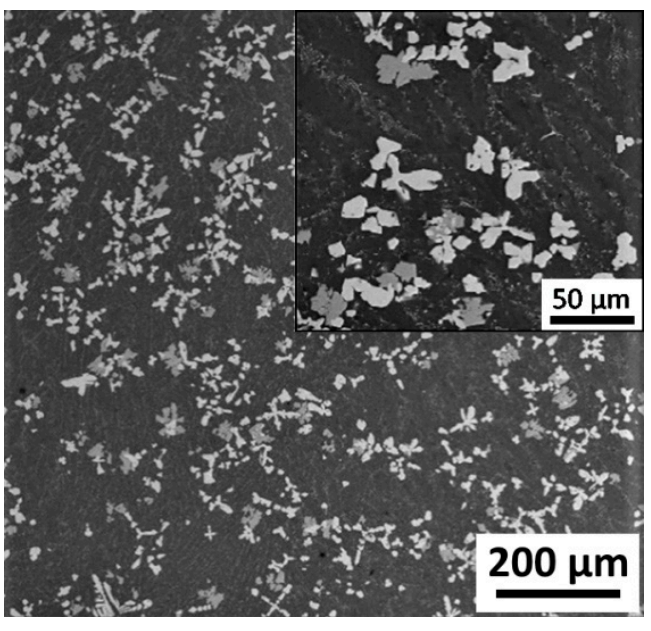

(f)

Figure 7. SEM images showing the primary crystals appeared in the as-cast Al-Ca-Mn-Ni alloys: (a) Al-8Ca-2Mn-1Ni (slow cooled); (b) Al-6Ca-3Mn-2Ni (slow cooled); (c) Al-8Ca-2Mn-1Ni (10 K/s); (d) Al-6Ca-3Mn-2Ni (10 K/s); (e) Al-8Ca-2Mn-2Ni (slow cooled); (f) Al-8Ca-2Mn-4Ni (10 K/s). 
The structure of the Al-8Ca-2Mn-1Ni alloy formed at a cooling rate of $10 \mathrm{~K} / \mathrm{s}$ (Figure 7c) represents a perfect natural composite and therein equiaxed small (no more than 10-15 $\mu \mathrm{m}$ ) $\mathrm{Al}_{10} \mathrm{Ca}(\mathrm{Mn}, \mathrm{Ni})_{2}$ ternary compound particles are evenly distributed on the superfine eutectic background. The latter contains about $8 \% \mathrm{Ca}$ and $0.8 \% \mathrm{Mn}$. Similarly, the Al-6Ca-3Mn$2 \mathrm{Ni}$ alloy structure consists of the eutectic and two types of primary crystals established to be $\mathrm{Al}_{10} \mathrm{Ca}(\mathrm{Mn}, \mathrm{Ni})_{2}$ of compact angular shape and $\mathrm{Al}_{6}(\mathrm{Mn}, \mathrm{Ca}, \mathrm{Ni})$ of coarse acicular shape (Figure $7 \mathrm{~d}$ and Table 4). It is apparent that if comparing two alloys, the $\mathrm{Al}-8 \mathrm{Ca}-2 \mathrm{Mn}-1 \mathrm{Ni}$ alloy has the most favourable structure as it contains fine primary crystals of less than 10-12 $\mu \mathrm{m}$ uniformly distributed in the ultrafine eutectic matrix. In the alloy $\mathrm{Al}-8 \mathrm{Ca}-2 \mathrm{Mn}-2 \mathrm{Ni}$, the $\mathrm{Al}_{10} \mathrm{Ca}(\mathrm{Mn}, \mathrm{Ni})_{2}$ primary crystals appeared along with bright $\mathrm{Al}_{8} \mathrm{Ca}(\mathrm{Ni}, \mathrm{Mn})_{2}$ equiaxed crystals, having visible facets (Figure 7e). Their amount increases with Ni content. In Al-8Ca$2 \mathrm{Mn}-3 \mathrm{Ni}$ and $\mathrm{Al}-8 \mathrm{Ca}-2 \mathrm{Mn}-4 \mathrm{Ni}$ alloys manufactured at a cooling rate of $10 \mathrm{~K} / \mathrm{s}$ (Figure $7 \mathrm{f}$ ), the structure consists of dispersed eutectic and uniformly distributed compact crystals of two types including grey $\mathrm{Al}_{10} \mathrm{Ca}(\mathrm{Mn}, \mathrm{Ni})_{2}$ and light $\mathrm{Al}_{8} \mathrm{Ca}(\mathrm{Ni}, \mathrm{Mn})$ (Table 4$)$.

Table 4. Composition of primary crystals according to EMPA analysis.

\begin{tabular}{|c|c|c|c|c|c|c|c|}
\hline \multirow{2}{*}{ Alloy } & \multirow{2}{*}{ Morphology } & \multirow{2}{*}{ Phase } & \multicolumn{5}{|c|}{ Concentration, Mass \% (at.\%) } \\
\hline & & & $\mathrm{Ca}$ & $\mathbf{N i}$ & $\mathrm{Fe}$ & Mn & Al \\
\hline \multirow{2}{*}{ Al-6Ca-3Mn } & Compact angular & $\mathrm{Al}_{10} \mathrm{CaMn}_{2}$ & $\begin{array}{c}9.5 \\
(7.5)\end{array}$ & - & - & $\begin{array}{c}24.4 \\
(14.2)\end{array}$ & $\begin{array}{r}66.1 \\
(78.3)\end{array}$ \\
\hline & Coarse acicular & $\mathrm{Al}_{6}(\mathrm{Mn}, \mathrm{Ca})$ & $\begin{array}{c}7.8 \\
(5.9)\end{array}$ & - & - & $\begin{array}{l}15.8 \\
(8.7)\end{array}$ & $\begin{array}{c}76.4 \\
(85.4)\end{array}$ \\
\hline \multirow{2}{*}{ Al-8Ca-2Mn } & Compact angular & $\mathrm{Al}_{10} \mathrm{CaMn}_{2}$ & $\begin{array}{c}9.7 \\
(7.7)\end{array}$ & - & - & $\begin{array}{c}22.9 \\
(13.3)\end{array}$ & $\begin{array}{l}67.4 \\
(79)\end{array}$ \\
\hline & Coarse acicular & $\mathrm{Al}_{6}(\mathrm{Mn}, \mathrm{Fe})$ & - & - & $5.6(3.1)$ & $\begin{array}{c}18.8 \\
(10.4)\end{array}$ & $\begin{array}{c}75.6 \\
(86.5)\end{array}$ \\
\hline Al-8Ca-2Mn-1Ni & Compact angular & $\mathrm{Al}_{10} \mathrm{Ca}(\mathrm{Mn}, \mathrm{Ni})_{2}$ & $\begin{array}{c}9.3 \\
(7.4)\end{array}$ & $\begin{array}{c}2.2 \\
(1.2)\end{array}$ & - & $\begin{array}{c}20.1 \\
(11.6)\end{array}$ & $\begin{array}{c}68.4 \\
(79.8)\end{array}$ \\
\hline \multirow{2}{*}{ Al-6Ca-3Mn-2Ni } & Compact angular & $\mathrm{Al}_{10} \mathrm{Ca}(\mathrm{Mn}, \mathrm{Ni})$ & $\begin{array}{c}7.8 \\
(5.9)\end{array}$ & $\begin{array}{c}0.8 \\
(0.4)\end{array}$ & - & $\begin{array}{c}18.0 \\
(10.1)\end{array}$ & $\begin{array}{c}73.4 \\
(83.6)\end{array}$ \\
\hline & Coarse acicular & $\mathrm{Al}_{6}(\mathrm{Mn}, \mathrm{Ca}, \mathrm{Ni})$ & $\begin{array}{c}6.9 \\
(5.1)\end{array}$ & $\begin{array}{c}2.6 \\
(1.3)\end{array}$ & - & $\begin{array}{l}10.8 \\
(5.9)\end{array}$ & $\begin{array}{r}79.7 \\
(87.7)\end{array}$ \\
\hline \multirow{2}{*}{ Al-8Ca-2Mn-(2-4)Ni } & Compact angular & $\mathrm{Al}_{10} \mathrm{Ca}(\mathrm{Mn}, \mathrm{Ni})_{2}$ & $\begin{array}{c}9.4 \\
(7.5)\end{array}$ & $\begin{array}{c}3.1 \\
(1.7)\end{array}$ & - & $\begin{array}{c}20.4 \\
(11.9)\end{array}$ & $\begin{array}{c}67.1 \\
(78.9)\end{array}$ \\
\hline & Coarse acicular & $\mathrm{Al}_{8} \mathrm{Ca}(\mathrm{Ni}, \mathrm{Mn})_{2}$ & $\begin{array}{l}10.5 \\
(8.8)\end{array}$ & $\begin{array}{c}26.4 \\
(15.2)\end{array}$ & - & $\begin{array}{c}4.5 \\
(2.8)\end{array}$ & $\begin{array}{c}58.6 \\
(73.2)\end{array}$ \\
\hline
\end{tabular}

For assessing processability at deformation the experimental Al-6Ca-3Mn, Al-8Ca2Mn, Al-8Ca-2Mn-(1-4)Ni alloys were chosen as their microstructure best fits the NMMC. Before hot rolling, the ingots of all selected alloys, as well as the FM180 ingot, were annealed at a temperature of $500{ }^{\circ} \mathrm{C}$ for $3 \mathrm{~h}$ to improve ductility. While the FM180 alloy has been established as a casting alloy, some research reported its wrought processing. Novel $\mathrm{Al}-\mathrm{Ca}$ hypereutectic alloys are expected to be uni-materials, a good choice either for casting or rolling. After annealing a substantial decrease in hardness and an increase in EC value are both due to sufficient change in eutectic particles shape.

During annealing, the fine eutectic-origin intermetallics acquire a rounded shape, the hardness of the alloys reasonably decreases and the electrical conductivity increases (Table 5). It is prominent that the FM180 alloy showed less response to spheroidisation due to the coarser eutectic structure. 
Table 5. Hardness and electrical conductivity of the alloys in the annealed condition.

\begin{tabular}{ccc}
\hline Alloy & HV & $\Omega, \mathbf{M S m} / \mathbf{m}$ \\
\hline Al-6Ca-3Mn & $62 \pm 1$ & $13.8 \pm 0.02$ \\
\hline Al-8Ca-2Mn & $73 \pm 3$ & $12.9 \pm 0.02$ \\
\hline Al-8Ca-2Mn-1Ni & $72 \pm 2$ & $13.2 \pm 0.02$ \\
\hline Al-8Ca-2Mn-2Ni & $73 \pm 2$ & $11.5 \pm 0.02$ \\
\hline Al-8Ca-2Mn-3Ni & $78 \pm 2$ & $10.9 \pm 0.02$ \\
\hline Al-8Ca-2Mn-4Ni & $80 \pm 2$ & $10.1 \pm 0.02$ \\
\hline AlSi18Cu1Mg1Ni1 (FM180) & $85 \pm 3$ & $14.5 \pm 0.13$
\end{tabular}

Furthermore, the Al-6Ca-3Mn, Al-8Ca-2Mn and FM180 ingots of $15 \mathrm{~mm}$ in thickness were rolled at $480{ }^{\circ} \mathrm{C}$ on a duo-mill 260 . The rolling was carried out at a $10 \%$ reduction for each pass. In 11 passes, the $\mathrm{Al}-6 \mathrm{Ca}-3 \mathrm{Mn}$ and $\mathrm{Al}-8 \mathrm{Ca}-2 \mathrm{Mn}$ alloys reached 2.06 and $2.22 \mathrm{~mm}$ in thickness without any breaks and other defects (Figure 8a). The FM180 was rolled down to $3.3 \mathrm{~mm}$ after 10 passes and broke down during the 11th pass (Figure $8 \mathrm{~b}$ ). While the FM180 alloy is a foundry alloy, hot stamping is also applied for manufacturing pistons $[20,21]$. Nevertheless, the ductility of this material appeared to be insufficient for obtaining quality hot-rolled sheet products. The Al-8Ca-2Mn-(1-4)Ni alloys were rolled at $500{ }^{\circ} \mathrm{C}$. As for the Al-8Ca-2Mn-(2-4)Ni samples, they showed transverse cracks after the first two passes. Conversely, the Al-8Ca-2Mn-1Ni alloy was rolled down to $3 \mathrm{~mm}$ in thickness without any visible cracks including those on the edge surfaces (Figure 8c). The primary intermetallics in all Ca-bearing alloys do not change their size and shape after deformation but become redistributed and aligned in the rolling direction. When it comes to the FM180 alloy, multiple cracks appeared in the silicon particles (Figure 9). The $\mathrm{Al}-6 \mathrm{Ca}-3 \mathrm{Mn}$ and $\mathrm{Al}-8 \mathrm{Ca}-2 \mathrm{Mn}$ hot-rolled sheets were annealed at $500{ }^{\circ} \mathrm{C}$ for $1 \mathrm{~h}$ and next subjected to cold rolling down to a thickness of $0.5 \mathrm{~mm}$.
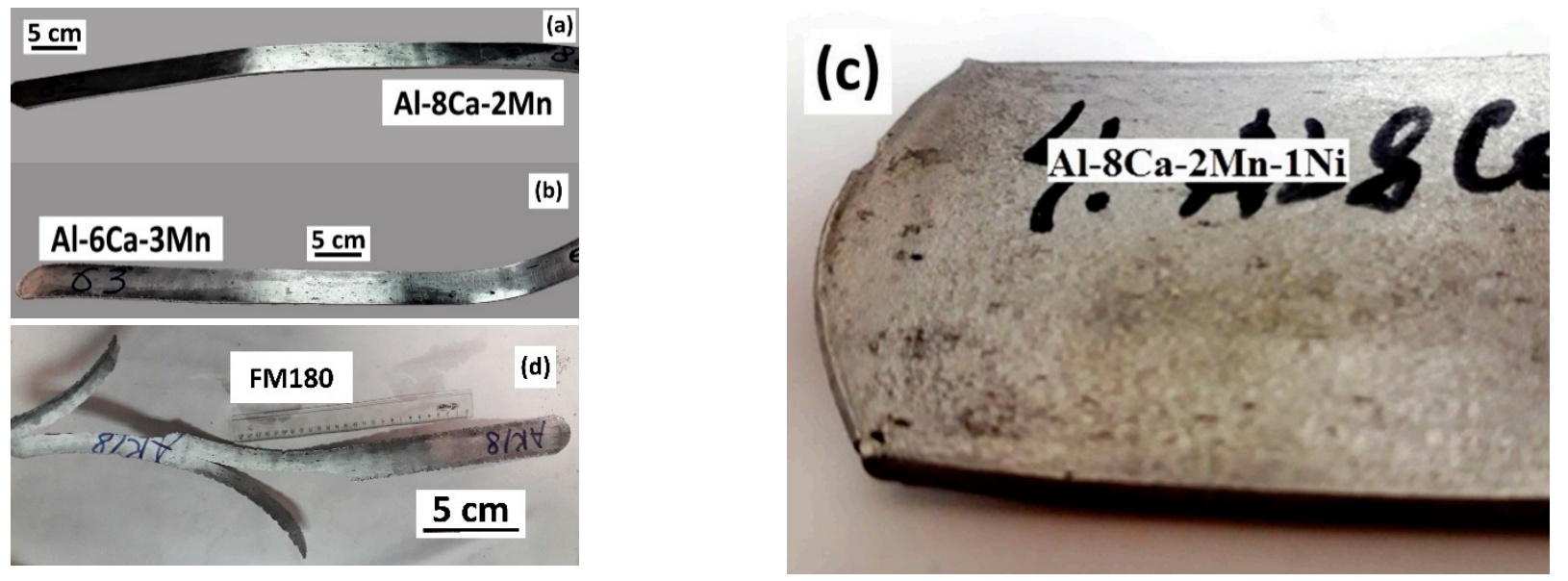

Figure 8. Hot-rolled sheets: (a) Al-6Ca-3Mn; (b) Al-8Ca-2Mn; (c) Al-8Ca-2Mn-1Ni; (d) FM180. 


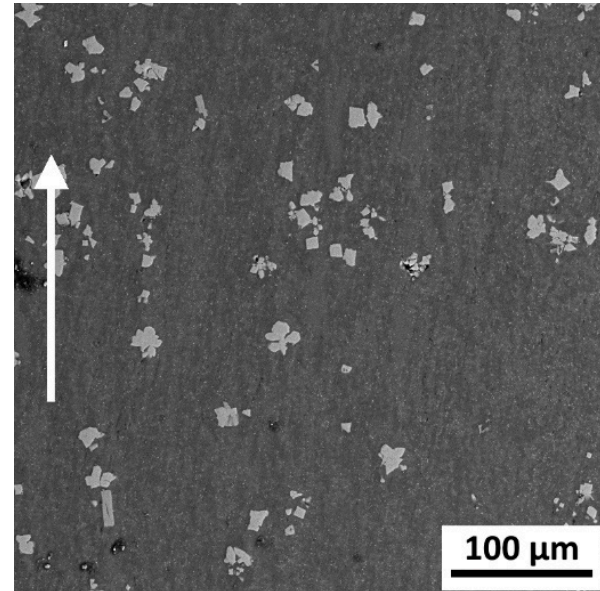

(a)

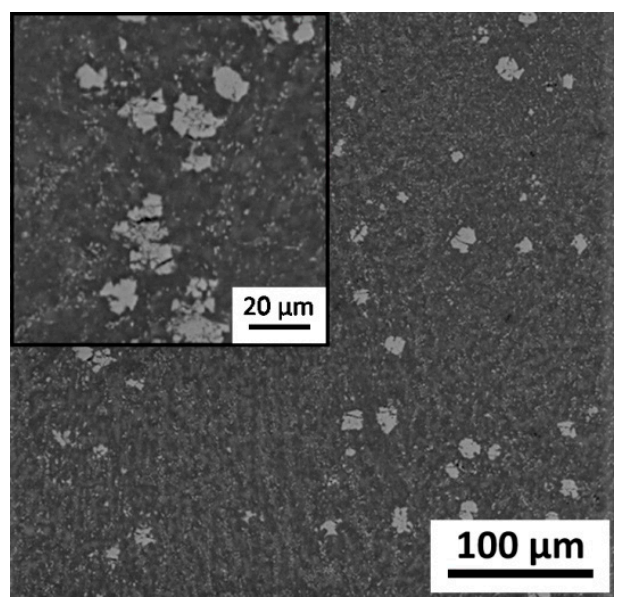

(c)

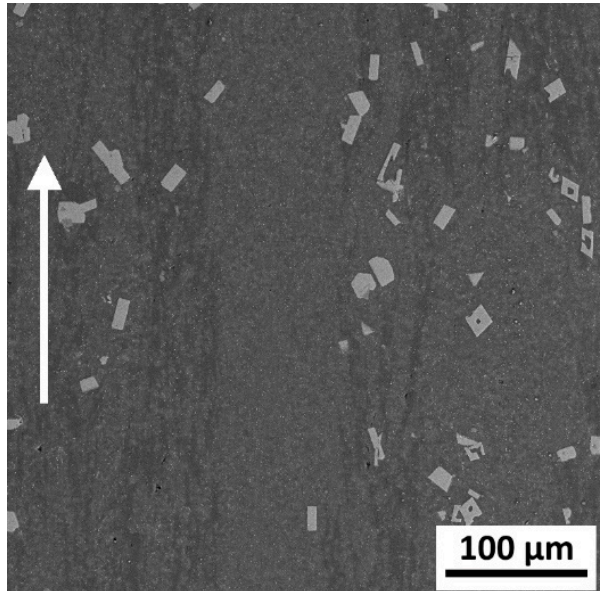

(b)

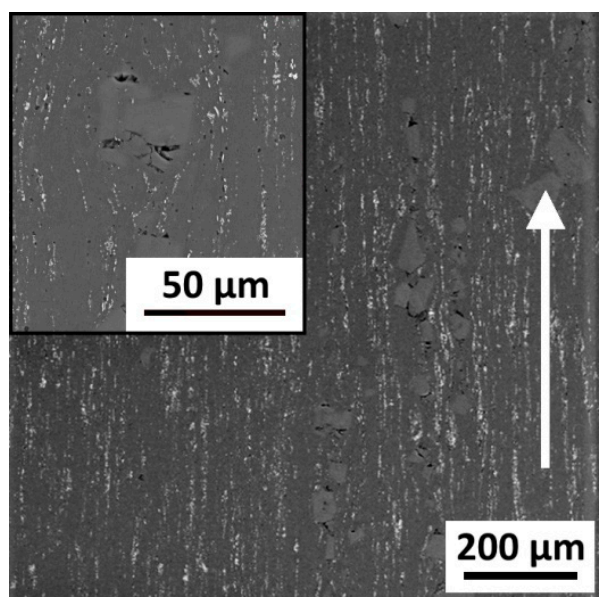

(d)

Figure 9. SEM images showing the microstructures of the hot-rolled sheets (arrows indicate the rolling direction): (a)—Al6Ca-3Mn (longitudinal direction); (b)-Al-8Ca-2Mn (longitudinal direction); (c)-Al-8Ca-2Mn-1Ni (transversal direction); (d) -FM180 (longitudinal direction).

Then, the tensile test specimens were cut from $\mathrm{Al}-6 \mathrm{Ca}-3 \mathrm{Mn}$ and $\mathrm{Al}-8 \mathrm{Ca}-2 \mathrm{Mn}$ hot-rolled and cold-rolled sheets and a Al-8Ca-2Mn-1Ni hot-rolled sheet. Additionally, unbroken parts of the FM180 hot-rolled sheet were taken for testing. Mechanical and some physical properties of the sheets are given in Table 6 . In terms of mechanical properties in the hot-rolled state, the quaternary $\mathrm{Al}-8 \mathrm{Ca}-2 \mathrm{Mn}-1 \mathrm{Ni}$ alloy is superior as compared to others.

Table 6. Physical and mechanical properties of the hot-rolled and cold-rolled sheets.

\begin{tabular}{|c|c|c|c|c|c|c|c|c|c|c|}
\hline \multirow[b]{2}{*}{ Alloy } & \multicolumn{5}{|c|}{ Hot-Rolled Sheets } & \multicolumn{5}{|c|}{ Cold-Rolled Sheets $+500,1$ h, Air } \\
\hline & $\begin{array}{c}\text { YS, } \\
\text { MPa }\end{array}$ & $\begin{array}{l}\text { UTS, } \\
\mathrm{MPa}\end{array}$ & $\begin{array}{l}\text { El, } \\
\%\end{array}$ & HV & $\begin{array}{c}\Omega, \\
\mathrm{MSm} / \mathrm{m}\end{array}$ & $\begin{array}{l}\text { YS, } \\
\text { MPa }\end{array}$ & $\begin{array}{l}\text { UTS, } \\
\text { MPa }\end{array}$ & $\begin{array}{l}\text { El, } \\
\%\end{array}$ & HV & $\begin{array}{c}\Omega, \\
\mathrm{MSm} / \mathrm{m}\end{array}$ \\
\hline Al-6Ca-3Mn & 158 & 250 & 4.3 & 73 & 17.42 & 145 & 160 & 2.2 & 65 & 11.68 \\
\hline Al-8Ca-2Mn & 162 & 260 & 3.3 & 82 & 17.10 & 164 & 166 & 0.25 & 71 & 15.00 \\
\hline Al-8Ca-2Mn-1Ni & 321 & 428 & 3.2 & 98 & 15.75 & - & - & - & - & - \\
\hline FM180 & 264 & 315 & 0.7 & 111 & 18.2 & - & 328 & 0.1 & 131 & 9.52 \\
\hline
\end{tabular}




\subsection{Coefficient of Thermal Expansion of the Ternary and Quaternary Alloys}

The alloys with the most favourable microstructure were selected for thermal expansion studying at $25-500{ }^{\circ} \mathrm{C}$. According to [22], the CTE value of a binary hypereutectic $\mathrm{Al}-18 \% \mathrm{Ca}$ alloy in the temperature range of $20-100{ }^{\circ} \mathrm{C}$ is $13.8 \times 10^{-6} 1 /{ }^{\circ} \mathrm{C}$. It is known from the literature that in the temperature range of $30-200{ }^{\circ} \mathrm{C}$, the $\mathrm{CTE}$ value of the permanent mould cast hypereutectic $\mathrm{Al}$ alloys containing $17-19 \% \mathrm{Si}$ is in the range $20 \cdot 10^{-6}-22 \times 10^{-6} 1 /^{\circ} \mathrm{C}$ [23]. As is shown in Table 7, Ni alloying slightly changes CTE value in the temperature range $20-100{ }^{\circ} \mathrm{C}$. Meanwhile, the $\mathrm{Al}-8 \mathrm{Ca}-2 \mathrm{Mn}$ and $\mathrm{Al}-8 \mathrm{Ca}-2 \mathrm{Mn}$ $1 \mathrm{Ni}$ alloys after $400{ }^{\circ} \mathrm{C}$ exhibit a decrease in CTE down to $(19-20) \times 10^{-6} 1 /{ }^{\circ} \mathrm{C}$.

Table 7. The CTE values of the alloys exhibited the most favourable microstructure.

\begin{tabular}{cccccc}
\hline \multirow{2}{*}{ Alloy } & \multicolumn{5}{c}{ CTE, $\mathbf{1 0}^{-\mathbf{6}} \mathbf{1} /{ }^{\circ} \mathbf{C}$} \\
\cline { 2 - 6 } & $\mathbf{2 5 - 1 0 0}$ & $\mathbf{2 5 - 2 0 0}$ & $\mathbf{2 5 - 3 0 0}$ & $\mathbf{2 5 - 4 0 0}$ & $\mathbf{2 5 - 5 0 0}$ \\
\cline { 2 - 6 } & 22.72 & 22.76 & 23.24 & 23.31 & 22.18 \\
\hline Al-6Ca-3Mn & 21.58 & 21.7 & 21.57 & 19.12 & 19.35 \\
\hline Al-8Ca-2Mn & 21.24 & 21.48 & 21.3 & 20.29 & 18.19 \\
\hline Al-8Ca-2Mn-1Ni & 20.44 & 21.01 & 21.61 & 21.98 & 22.19 \\
\hline Al-8Ca-2Mn-4Ni & &
\end{tabular}

\section{Discussion}

Summing up the results, the Al-6Ca-3Mn, Al-8Ca-2Mn and Al-8Ca-2Mn-1Ni alloys may be reasonably considered as a promising basis for developing novel alloys for special applications as an alternative to the hypereutectic Al-Si alloys. Al-Ca alloys show the same fraction of primary crystals as those in the FM180 alloy ( $\sim 5$ vol. $\%)$ but have more favourable phase transformation temperatures. As follows from the thermal analysis (Figure 10), the $\mathrm{Al}-6 \mathrm{Ca}-3 \mathrm{Mn}$ and $\mathrm{Al}-8 \mathrm{Ca}-2 \mathrm{Mn}$ alloys have a higher solidus temperature as compared to the FM180 alloy. This feature implies the opportunity for conducting the annealing of the ingots at a higher temperature and higher thermal stability in the exploiting conditions. The results obtained by direct and differential thermal analysis appeared to be virtually similar.
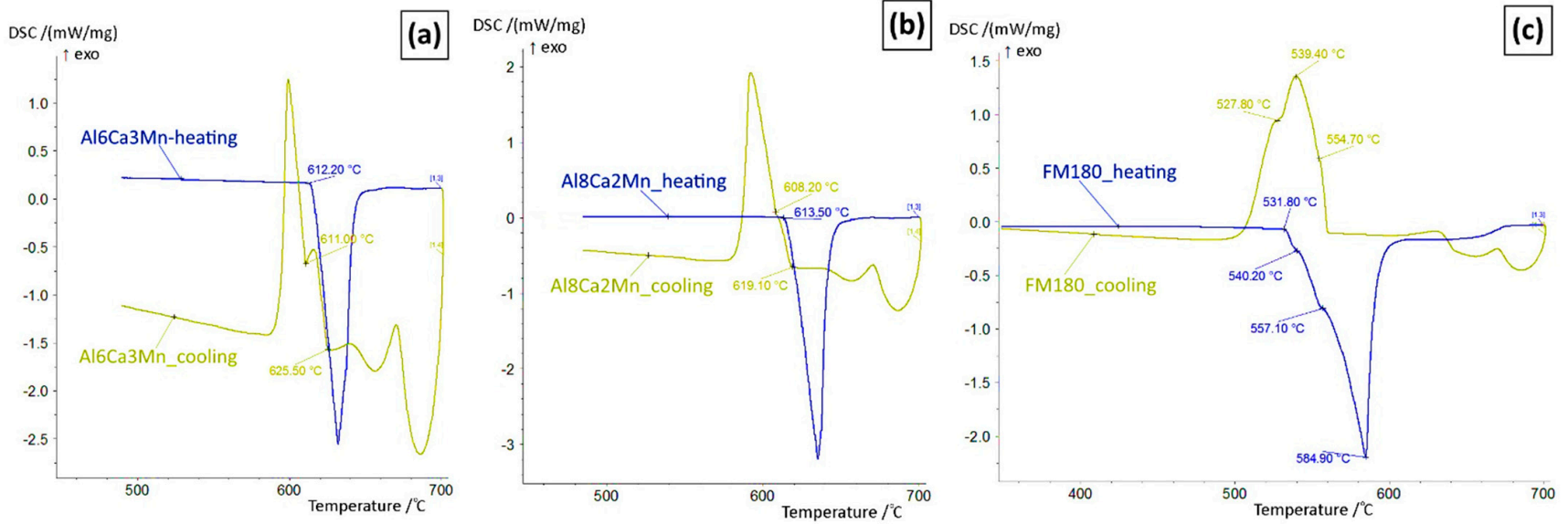

Figure 10. Results of the differential thermal analysis and direct thermal analysis on the: (a) Al-6Ca-3Mn; (b) Al-8Ca-2Mn; (c) FM180 alloys. 
Since the Thermo-Calc software does not take into account the formation of ternary compounds in the Al-rich angle, the experimental Al-Ca-Mn-Ni liquidus projection should be different from the calculated one. Hence, in addition to the ternary $\mathrm{Al}_{10} \mathrm{Ca}(\mathrm{Mn}, \mathrm{Ni})_{2}$ phase which appeared in the alloys containing more than $1 \% \mathrm{Ni}$, there is a ternary compound $\mathrm{Al}_{8} \mathrm{Ca}(\mathrm{Ni}, \mathrm{Mn})_{2}$ based on the $\mathrm{Al}_{8} \mathrm{CaNi}_{2}$ phase. However, the $\mathrm{Al}_{9} \mathrm{CaNi}$ compound formed in the Al-Ca-Ni-La alloys is indicated in [12]. In the handbook [24], the presence of both $\mathrm{Al}_{8} \mathrm{CaNi}_{2}$ and $\mathrm{Al}_{9} \mathrm{CaNi}$ phases is alleged in the Al-rich angle of the Al-Ca-Ni ternary system. Having conducted the current study, we can propose the appearance of the Al-Ca-Mn-Ni diagram in the Al-rich angle (Figure 11). Nevertheless, the existence of two ternary compounds $\mathrm{Al}_{8} \mathrm{CaNi}_{2}$ and $\mathrm{Al}_{9} \mathrm{CaNi}$ requires experimental verification. According to the hypothetical view of the phase diagram, there are five primary crystallisation regions: $\mathrm{Al}_{4} \mathrm{Ca}+\mathrm{L} ; \mathrm{Al}_{3} \mathrm{Ni}+\mathrm{L} ; \mathrm{Al}_{6} \mathrm{Mn}+\mathrm{L} ; \mathrm{Al}_{10} \mathrm{CaMn}_{2}+\mathrm{L} ; \mathrm{Al}_{8} \mathrm{CaNi}_{2}+\mathrm{L}$. As is shown in the work $[25,26]$, the $\mathrm{T}\left(\mathrm{Al}_{16} \mathrm{Mn}_{3} \mathrm{Ni}\right)$ compound indicated in the diagram is present in the ternary Al-Mn-Ni system. Moreover, three invariant reactions including two peritectic $\mathrm{L}+\mathrm{Al}_{3} \mathrm{Ni} \rightarrow(\mathrm{Al})+\mathrm{Al}_{6} \mathrm{Mn}+\mathrm{Al}_{8} \mathrm{CaNi}_{2}$ (point $\mathrm{P} 1$ ); $\mathrm{L}+\mathrm{Al}_{6} \mathrm{Mn} \rightarrow(\mathrm{Al})+\mathrm{Al}_{10} \mathrm{Mn}_{2} \mathrm{Ca}+\mathrm{Al}_{8} \mathrm{CaNi}_{2}$ (point P2) and one eutectic $\mathrm{L} \rightarrow(\mathrm{Al})+\mathrm{Al}_{4} \mathrm{Ca}+\mathrm{Al}_{10} \mathrm{Mn}_{2} \mathrm{Ca}+\mathrm{Al}_{8} \mathrm{CaNi}_{2}$ (point $\mathrm{E}$ ) are drawn.

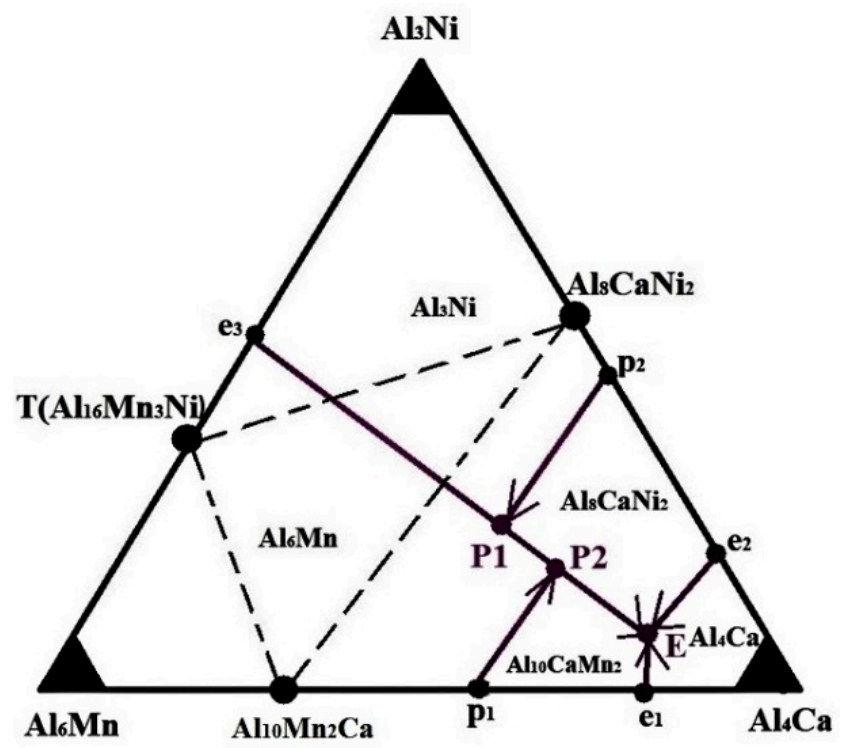

Figure 11. Hypothetical distribution of the solid phase fields in the Al-Ca-Mn-Ni system.

The Ca-bearing alloys are better in deformation than the Al-Si piston alloy due to the remarkable fineness of the eutectic structure. Poor processability of the Al-8Ca-2Mn(2-4)Ni may be associated with a high number of the $\mathrm{Al}_{8} \mathrm{CaNi}_{2}$ phase. The latter, despite having a compact shape and small size of $40 \mu \mathrm{m}$, appears to act as a stress raiser causing brittle interfacial fracture (Figure 12). In contrast, the $\mathrm{Al}_{10} \mathrm{Ca}(\mathrm{Mn}, \mathrm{Ni})_{2}$ crystals, likely less strong, break in a fragile manner simultaneously with the matrix that ensures fewer stresses. Notwithstanding the cracks that appeared at the very beginning of the rolling, the Al-8Ca-2Mn-(2-4)Ni alloys were successful in a way similar to the FM180 alloy. That is stipulated by the superfine ductile matrix surrounding the brittle $\mathrm{Al}_{8} \mathrm{CaNi}_{2}$ crystals. 


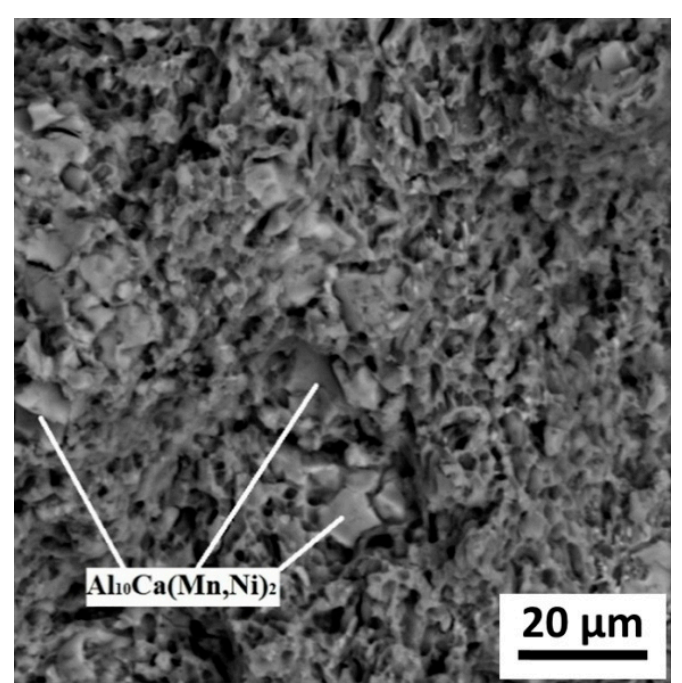

(a)

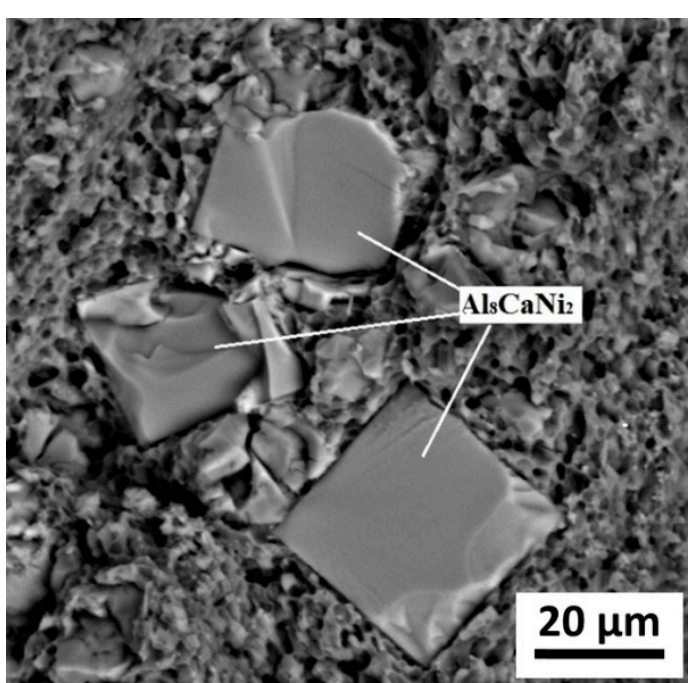

(b)

Figure 12. Fracture surfaces of the hot-rolled samples: (a) Al-8Ca-2Mn-1Ni; (b) Al-8Ca-2Mn-2Ni.

Thus, we can reasonably conclude that, despite the promising natural composite structure of the Al-8Ca-2Mn-(2-4)Ni alloys, they are not feasible in hot deformation due to the presence of the high fraction of brittle compound. Therefore, the stiffness of the primary crystals should be comparable to that of the matrix (surrounding eutectic structure) that may be noted as a requirement to the structure of the new Al-Ca hypereutectic natural composites. With a noticeable difference in strength between matrix and primary crystals, even if the latter has a small size and uniform distribution within the bulk, they appear to become places where brittle deformation occurs. Summing up, the $\mathrm{Al}_{10} \mathrm{Mn}_{2} \mathrm{Ca}$ crystals mostly meet the foregoing requirements.

\section{Conclusions}

(1) The composition and morphology of the primary crystals that appeared in the hypereutectic $\mathrm{Al}-(3-10) \mathrm{Ca}-(0-3) \mathrm{Mn}-(0-4) \mathrm{Ni}$ alloys were studied using experimental and computational methods including the construction of the liquidus projections. As a result, the hypothetic Al-Ca-Mn иAl-Ca-Mn-Ni phase diagrams were proposed in an Al-rich angle.

(2) An appearance of the $\mathrm{Al}_{10} \mathrm{CaMn}_{2}$ compound, unknown in the $\mathrm{X}$-ray databases, was established in the Al-Ca-Mn system. It was found that the crystal lattice belongs to the $\mathrm{tP52} / 2$ space group and has the parameters $\mathrm{a}=1.2845 \mathrm{~nm}$ and $\mathrm{c}=0.5134 \mathrm{~nm}$. The new compound was observed with a relatively compact shape and medium size of $20 \mu \mathrm{m}$.

(3) The ternary $\mathrm{Al}-6 \mathrm{Ca}-3 \mathrm{Mn}$ and $\mathrm{Al}-8 \mathrm{Ca}-2 \mathrm{Mn}$ alloys were found to have high processability at hot and cold rolling. A crack-free hot-rolled sheet was manufactured from the quaternary $\mathrm{Al}-8 \mathrm{Ca}-2 \mathrm{Mn}-1 \mathrm{Ni}$ alloy. High plasticity at the rolling of the hypereutectic Al-Ca alloys was substantiated.

(4) A comparison of the physical and mechanical properties along with processability of the Al-6Ca-3Mn, Al-8Ca-2Mn and Al-8Ca-2Mn-1Ni experimental alloys and the commercial FM180 piston alloy with FM180 grade silumin was performed. The Al-8Ca$2 \mathrm{Mn}-1 \mathrm{Ni}$ was found to be an effective basis for the development of new-generation natural metal matrix composite alternatives to the Al-Si counterparts. What is more, experimental alloy exhibit microstructure characterised both by small-sized primary crystals and fine eutectic structure. In this respect, no special modification operation during melting and casting is required.

(5) It is shown that several features of the primary crystals must be maintained for achieving the appropriate performance of the Al-Ca hypereutectic alloys. While some primary crystals with equiaxed shape and uniform distribution cannot act as a 
structural component in the new alloys, the $\mathrm{Al}_{10} \mathrm{Mn}_{2} \mathrm{Ca}$ compound was revealed to be most appropriate.

Author Contributions: Conceptualisation, E.N.; investigation, V.D. and T.S.; methodology, V.D., M.B. and A.L.; resources, V.D., M.B., T.S. and A.L.; supervision, E.N.; writing-original draft, E.N.; writing-review and editing, E.N. and P.S. All authors have read and agreed to the published version of the manuscript.

Funding: This research was funded by the Russian Science Foundation (project no. 20-19-00746).

Institutional Review Board Statement: Not applicable.

Informed Consent Statement: Not applicable.

Data Availability Statement: Data are available from the corresponding author on reasonable request.

Acknowledgments: The authors are grateful to Aleksandr Koshmin, a postgraduate student of the Department of Metal Forming, NUST MISiS, for experimental alloys rolling.

Conflicts of Interest: The authors declare no conflict of interest.

\section{References}

1. Glazoff, M.; Khvan, A.; Zolotorevsky, V.; Belov, N.; Dinsdale, A. Casting Aluminum Alloys: Their Physical and Mechanical Metallurgy, 2nd ed.; Elsevier: London, UK, 2018; p. 608. [CrossRef]

2. Gloria, A.; Montanari, R.; Richetta, M.; Varone, A. Alloys for Aeronautic Applications: State of the Art and Perspectives. Metals 2019, 9, 662. [CrossRef]

3. Graf, A. Aluminum alloys for lightweight automotive structures. In Materials, Design and Manufacturing for Lightweight Vehicles, 2nd ed.; Woodhead Publishing in Materials: Cambridge, UK, 2021; pp. 97-123. [CrossRef]

4. Jorstad, J.; Apelian, D. Hypereutectic Al-Si Alloys: Practical Casting Considerations. Int. J. Metalcast. 2009, 3, 13-36. [CrossRef]

5. Zhang, H.-H.; Duan, H.; Shao, G.; Xu, L. Microstructure and mechanical properties of hypereutectic Al-Si alloy modified with Cu-P. Rare Met. 2008, 27, 59-63. [CrossRef]

6. Naumova, E.A. Use of Calcium in Alloys: From Modifying to Alloying. Russ. J. Non-Ferr. Met. 2018, 59, 284-298. [CrossRef]

7. Belov, N.A.; Naumova, E.A.; Akopyan, T.K.; Doroshenko, V.V. Phase Diagram of the Al-Ca-Fe-Si System and Its Application for the Design of Aluminum Matrix Composites. JOM 2018, 70, 2710-2715. [CrossRef]

8. Belov, N.A.; Naumova, E.A.; Akopyan, T.K.; Doroshenko, V.V. Design of Multicomponent Aluminium Alloy Containing 2 wt.\% $\mathrm{Ca}$ and $0.1 \mathrm{wt}$ \% Sc for Wrought and Cast Products. JALCOM 2018, 762, 528-536. [CrossRef]

9. Belov, N.A.; Naumova, E.A.; Bazlova, T.A.; Doroshenko, V.V. Phase Composition and Hardening of Castable Al-Ca-Ni-Sc Alloys Containing 0.3\% Sc. Met. Sci. Heat Treat. 2017, 59, 76-81. [CrossRef]

10. Naumova, E.A.; Akopyan, T.K.; Letyagin, N.V.; Vasina, M.A. Investigation of the structure and properties of eutectic alloys of the Al-Ca-Ni system containing REM. Non-Ferr. Met. 2018, 2, 24-29. [CrossRef]

11. Rogachev, S.O.; Naumova, E.A.; Vasileva, E.S.; Magurina, M.Y.; Sundeev, R.V.; Veligzhanind, A.A. Structure and mechanical properties of Al-Ca alloys processed by severe plastic deformation. Mater. Sci. Eng. A 2019, 767, 13841. [CrossRef]

12. Akopyan, T.K.; Belov, N.A.; Naumova, E.A.; Letyagin, N.V.; Sviridova, T.A. Al-matrix composite based on the Al-Ca-Ni-La system additionally reinforced by the L12 type nanoparticles. Trans. Nonferrous Met. Soc. China 2020, 30, 850-862. [CrossRef]

13. Belov, N.A.; Naumova, E.A.; Doroshenko, V.V.; Bazlova, T.A. Effect of manganese and iron on the phase composition and microstructure of aluminum-calcium alloys. Tsvetnye Met. 2017, 8, 66-71. [CrossRef]

14. Rogachev, S.O.; Naumova, E.A.; Sundeev, R.V.; Tabachkova, N.Y. Structural and phase transformations in a new eutectic Al-Ca-Mn-Fe-Zr-Sc alloy induced by high pressure torsion. Mater. Lett. 2019, 243, 161-164. [CrossRef]

15. Muggerud, A.M.F.; Mørtsell, E.A.; Li, Y.; Holmestad, R. Dispersoid strengthening in AA3xxx alloys with varying Mn and Si content during annealing at low temperatures. Mater. Sci. Eng. A 2013, 567, 21-28. [CrossRef]

16. Thermo-Calc Software TTAL5 Al-Alloys. Available online: www.thermocalc.com (accessed on 20 April 2021).

17. Shelekhov, E.V.; Sviridova, T.A. Programs for X-ray analysis of polycrystals. Met. Sci. Heat Treat. 2000, 42, 309-313. [CrossRef]

18. Yaniv, G.; Vidal, D.; Fuks, D.; Meshi, L. Bonding and Stability of Ternary Structures in the CeT2Al20 (T=Ta, W, Re) and YRe2Al20 Alloys. Metals 2020, 10, 422. [CrossRef]

19. Janssen, Y.; Angst, M.; Dennis, K.W.; McCallum, R.W.; Canfield, P.C. Differential thermal analysis and solution growth of intermetallic compounds. J. Cryst. Growth 2005, 285, 670-680. [CrossRef]

20. Zhu, Q.; Rassili, A.; Midson, S.P.; Hu, X.G. Thixoforming of Hypereutectic AlSi12Cu2NiMg Automotive Pistons. Solid State Phenom. 2019, 285, 446-452. [CrossRef]

21. Prudnikov, A.N. Deformable heatproof transeutectic silumin for pistons. Steel Transl. 2009, 39, 456. [CrossRef]

22. Naumova, E.A.; Petrov, M.A.; Stepanov, B.A.; Vasilieva, E.S. Stamping with torsion of the Al-Ca alloy workpiece with high concentration of $\mathrm{Al}_{4} \mathrm{Ca}$. Tsvetnye Met. 2019, 1, 66-71. [CrossRef] 
23. Hatch, J.E. Aluminum: Properties and Physical Metallurgy; American Society for Metals: Cleveland, OH, USA, 1984; pp. 320-350.

24. Petzow, G.; Effenberg, G. Ternary Alloys: A Comprehensive Compendium of Evaluated Constitutional Data and Phase Diagrams; Wiley-VCH: Berlin, Germany; Weinheim, Germany, 1990; Volume 3, p. 647.

25. Belov, N.A.; Aksenov, A.A.; Eskin, D.G. Multicomponent Phase Diagrams: Applications for Commercial Aluminum Alloys; Elsevier: Amsterdam, The Netherlands, 2005; pp. 223-256. [CrossRef]

26. Mondolfo, L.F. Aluminium Alloys: Structure and Properties; Butterworths: London, UK, 1976; pp. 806-841. [CrossRef] 